\title{
Untranslatability in the Visual Arts Examples from Visual Concrete Poetry*
}

Amrita R. Joshi

\begin{abstract}
This paper attempts to relate some of the intrinsic and extrinsic criteria implied in the notion and nature of untranslatability in inter-semiotic translation. In particular, this paper attempts to explore the translatability/ untranslatability inherent in certain forms of visual art with specific reference to an intermedium between visual arts and literature, broadly known as Concrete poetry which includes visual, auditory and kinetic forms.

It attempts to explore what kind of semiotic system/s would be able to replace language as the target system and would it then be possible to translate a visual art system into an extra-linguistic one? Without denying the importance of natural languages as the most easily perceived and universally recognized systems, it may be possible for a visual poetic text to be 'translated' into, say, a piece of music, of sculpture, a cinematic image, a painting and so on. Taking individual examples from the international corpus of visual concrete poetry, this paper also examines the nature of untranslatability in such texts with reference to script and language, and iconicity.
\end{abstract}

\section{Introduction}

The paper explores a specialized variant of poetry which is an 'intermedium' " between the visual and the verbal, and the practitioners of this poetry include not only poets but also painters, graphic artists, typographers etc. Visual concrete poetry as an intermedium where "two or more discrete media are conceptually fused" and are 
"inseparable in the essence of the artwork" (Higgins 1984:138) signifies the need to revisit the concept of translatability. There have been extensive debates about the application of linguistic concepts to the field of visual art. ${ }^{2}$ The motivation, however, in doing so here also results from the intermediality and intersemioticity that visual concrete poetry partakes of. The act of translation thus also needs to address factors of simultaneity, co-functioning, integration and overlap.

In a discussion on 'Translation and the Construction of Identity', a special panel on "The Verbal, The Visual, The Translator", Klaus Kaindl and Riitta Oittinen (2004) remark on how

far too often translators are assumed to be dealing with the verbal only, which is why visual elements and visual literacy tend to be neglected both in translator training and in research on translation and interpreting.

They add:

\begin{abstract}
Although the so-called cultural turn has opened up new research angles and opportunities in Translation Studies, scholars in the field still tend to show a distinct preference for researching the linguistic dimension of texts ...Today, the verbal is no longer the central means of representing and communicating meaning in many contexts; more often, the verbal and visual modes work together to communicate multiple and complex messages simultaneously.
\end{abstract}

("The Verbal, the Visual..." paras:1 and 2)

The responsiveness of visual concrete poetry to this critical enquiry is here carried forward by looking at existing concepts in Translation Studies and alternative approaches. Roman Jakobson identifies 'equivalence' as the central problem in all types of translation stating that there can never be complete equivalence since each unit 
contains within itself a set of non-transferable associations and connotations. And therefore, he declares that all poetic art is technically untranslatable. ${ }^{3}$ Thus, he states:

Only creative transposition is possible: either intralingual transposition-from one poetic shape into another, or interlingual transposition-from one language into another, or finally intersemiotic transposition-from one system of signs into another, e.g. from verbal art into music, dance, cinema or painting.

(Jakobson qtd. in Brower 1959:238)

When a translation of a particular work or text is to be undertaken, the nature of the form and the possibilities of translation thereof need to be considered. If, as Bassnett points out, extra-linguistic criteria need to be taken into account even for linguistic translation, it follows that in systems which are extra-linguistic, the semiotic processes need to be redefined according to the structures of those systems. Thus, in the case of extra-linguistic systems which possess different kinds of structures, we may call for a systemic equivalence which must concern itself with what Popovic refers to as the 'invariant core' of the text:

[T]he invariant core...is represented by stable, basic...elements in the text... Transformations, or variants, are those changes which do not modify the core of meaning but influence the expressive form. In short, the invariant can be defined as that which exists in common between all existing translations of a single work.

(Bassnett 1980:26-27)

This idea will be taken up further, when this paper investigates the nature of intersemiotic translation. We now turn to the nature of visual concrete poems whose potential for 'translatability' is taken up and problematised in this paper. 


\section{The Concrete Poem}

The Concrete Poetry movement with its beginnings in the 1950s and continuing up to the present with post-concrete creations including New Media Poetry and Conceptional Poetry is a manifestation of the avant-garde in the fields of literature and in the visual arts. Concrete Poetry as a movement initially reacted to conventionalized linear syntactic structures, basing its creative expression on the fact that the machine age, the era of technology, the speed and the pace of modern life and the nature of contemporary languages required a different form of expression than what was seen in conventional forms of verse. According to the Concretists, the new world required new modes of reading and expression. This search led them to the individual units - the word and the letter.

Mike weaver (1976) distinguishes three types of Concrete Poetry: visual (optic), phonetic (sound) and kinetic (moving in a visual succession). According to him,

The act of perception itself is the first preoccupation of concrete poetry. The optic or visual poet offers the poem as a constellation in space; the kinetic poet offers it as a visual succession; the phonetic poet offers it as an auditory succession

(Weaver 1976 (6):294)

Many of these poems require the cultivation of a different approach to reading as they consist of "a single word or phrase" or a minimal text

which is subjected to systematic alterations in the order and position of the component letters, or else are composed of fragments of words... letters, numbers and marks of punctuation

(Abrams 1993:35) 
They explore the spatio-temporality of letterforms and the blank space of the page in their engagement with type fonts and sizes, patterns, colours etc. They seek to incorporate visual, auditory and kinetic elements which are revealed during the 'reading' of such poems. The concrete poem becomes a 'poem-product.' It deals with the communication of its own structure-content and thus involves a process of metacommunication. In his essay titled "Reflections on Verbivocovisual Ideograms", Cluver (1982) demonstrates how concrete poems "are all spatio-temporal structures" which "exploit the visual, aural, and semantic qualities of their verbal material..." (Cluver 1982 3(3):137).

\section{Forerunners}

In "Un coup de dés" (1897), Stephane Mallarme realized the function of the blank space on the page and the poem as a function of that blank space interacting with it and establishing a visual syntax. Ezra Pound was inspired by Ernest Fenollosa's study titled The Chinese Written Character as a Medium for Poetry (1920) and used the ideogrammic method in his 'Cantos.' Apollinaire is known for his 'calligrams' which is a combination of "script, design and thought", one, which, according to John Massin,

represents the shortest route which can be taken for expressing a thought in material terms, and for forcing the eye to accept a global view of the printed word

(Massin 1970:157)

Before Apollinaire, these were known as figured verses or pattern poems of different kinds and are seen at different points of time in ancient Greece, in the Far-East, in India, Germany, France and England. ${ }^{4}$

Other forerunners to Concrete poetry include James Joyce and E.E. Cummings. Joyce utilized syntactic subversion and used 'wordideograms.' It is from Joyce that the movement derives its term 
'verbivocovisual' which sums up its essence. E.E. Cummings, known as a typographical poet, ${ }^{5}$ experimented with the disruption of conventional syntactic structures and placed great importance on the physical aspects of the word and freedom from punctuation.

In addition to all these, the movement drew its inspiration from various other forms such as Eisenstein's ideogrammic montage technique in cinema, Anton Webern's music and the Concrete Art of Piet Mondrian, Josef Albers and Max Bill. ${ }^{6}$

\section{Translatability in Visual Concrete Poetry: Definition and Scope}

The Encyclopedic Dictionary of Semiotics defines translatability as "the initial interchangeability of two semiotic entities, pertaining to two different systems, under certain postulated equivalence conditions" (Sebeok 1986). In these visual poems-whether they are constructivist or expressionist - the strategies employed by the poet in rendering them so is a starting point in any attempt at understanding the translation potential of such poems. The nature of such an 'intermedium' stresses that although one may approach it through an all-pervasive linguistic model, the generic features of the system itself such as isomorphism, multi-directionality and meta-communication raise questions about the use of the term 'translation' in this context. One major thread that we can work with is Jakobson's identification of intersemiotic translation and especially his term 'transmutation'.

If one applies the term 'translation' per se to an extra-linguistic system, one looks for a recreation or reproduction in another language wherein there are replaceable units although exact replaceability posits a problem and thereby suggests the problem of linguistic equivalence, loss and gain. However, the terms 'transmutation' and 'transposition' provide greater room for maneuver.

Visual Concrete Poetry's complex condition as a fusion of two symbol systems is further dynamized by its generic features which 
mark a radical movement away from conventional considerations of reading, meaning and interpretation associated with the comprehension of poetry. The intermedium itself suggests its own intertextualities, incorporating as it does the fusion of two systems and the whole range of textualities that each system brings with it into this fusion. It thus calls for deeper understanding of this synthesis and co-existence of the verbal and the visual and the issues involved in the transposition of such configurations.

Most visual poems like other visual forms such as painting, sculpture etc have tightly composed forms. This means that the form that appears to emerge on the plane or surface or paper is essentially a carefully structured entity meeting certain systemic requirements. Thus, any attempt at transposing these composite structures would involve an attempt at identifying or isolating certain components. In the case of visual poems which use language as material first and then as a conveyor of semantic content, the script, the typeface, the nonverbal signs etc are an integral part of the composite structure. Therefore, untranslatability as also translatability in the case of this visual mode of poetic expression derives from the nature of individual poems, their formal elements and their graphic structure.

\section{Language, Script, Iconicity: Translatability of Visual Concrete Poems}

Concrete Poetry: A World View, an anthology edited by Mary Ellen Solt with a comprehensive introduction to the worldwide movement is an important text which draws one's attention to the translatability of visual poems. In this anthology of 140 poems from around the world, three categories are seen in terms of 'translation':

1. There are 13 translations in the interlingual sense i.e from one language into another.

2. Poems that have not been translated are 'interpreted' by means of a word gloss and comments. 
3. An overlap is seen here wherein poems concentrating on physical/formal elements are interpreted using the poets' and the editor's comments on these texts.

In a visual poem, script and language are foregrounded over and above semantic issues. Thus the manner in which script contributes to the visual poem and the constraints that language as a system imposes or liberates the text from, are important considerations in the visual poem. The nature of the script and the manner in which the script carries the language, has an influential part to play in determining the iconicity of the text. In the poem "Epithalamium II" (Solt 1970:114) the visual iconicity of the entire poem can be attributed to the typographical choice made by the poet in the context of the script and the language itself which creates distinctive elements 'she' and 'he.'

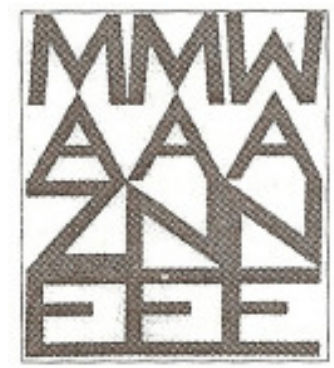

Figure 1: "maze" by Ronald Johnson, Solt 251

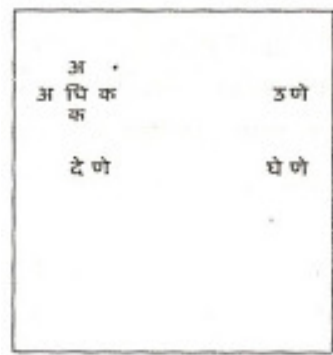

Figure 2: "vyavahar" by R.K. Joshi, Rava 8 
A similar phenomenon is at work in Ronald Johnson's "maze" (Figure 1) and R. K. Joshi's "vyavahar" (Figure 2); as also in Seiichi Nikuni's "Rain" (Wildman 1969:5) and Frans Vanderlinde's "EliminationIncarnation" (Wildman, 1969:77). In Vanderlinde's poem, it is the specificity of the typeface used, which through the basic element of the 'line' creates the journey from elimination to incarnation. In Johnson's 'maze", the signifiers 'MANE' and 'WANE' emerge out of a vertical reading which is induced after the reader-viewer aborts a 'conventional' left-to-right reading. This inducement of the vertical reading by the typographical choices made by the poet lead to the viewing of the signifiers 'mane' and 'wane' where the ' $M$ ', the ' $W$ ', and the ' $\mathrm{Z}$ ' and ' $\mathrm{N}$ ' are features of mirroring and reversal. In R.K. Joshi's "Vyavahar" ("Dealings"), the gains and the losses affected through life's dealings are visually reinforced by the iconic play of script and language. The signification of addition and subtraction contained by a frame within a frame engages with the activity of giving and receiving which lies outside the frames.

Eugene Wildman's afterword in his Anthology of Concretism particularly points out this collaboration between script and the poet's visual achievement when he writes:

Concrete Poetry aims in general at the ideogrammic state. The poets pattern the letters of words in much the same way that a Japanese calligrapher patterns the strokes of a character. By no means, however, are all Chinese characters pictures of things they represent. Language is not that simple, and this is a too-popular fallacy about ideograms. In the poem "rain" the calligrapher Seiichi Niikuni became the poet Seiichi Niikuni when his design was able to achieve the identification between the word-as-picture and the wordas-sign. A Chinese character is not, by itself, a concrete poem. It requires the presence of an artist who will $d o$ something with the material.

$(1969: 162-163)$ 
This leads us to two possibilities. Let us see what the issues in translation thereof are:

Same script and different languages: This is a relatively simple situation for the translation of a visual poem relying heavily on word elements. These are thus intralingual translations which syntactically and semantically reproduce the units of the source text in the target text. For instance: Haroldo de Campos" "se nasce morre nasce - if to be born to die" (Figures 3a and 3b). Here, for instance it is important that the translation retains the information area marked by 'se'. Eugen Gomringer's "silencio" (Figure 4) derives its referential meaning from its use of the linguistic vehicle 'silencio', whose substitution could lend the poem a different meaning altogether. What is to be transposed is the exploration of its visual-verbal configuration which is its structurecontent, its spatio-temporality, its multi-directionality, its inward focus. Similarly, Arrigo Lora-Totino's "spazio" (Figure 5) can be re-rendered conceptually in other languages.
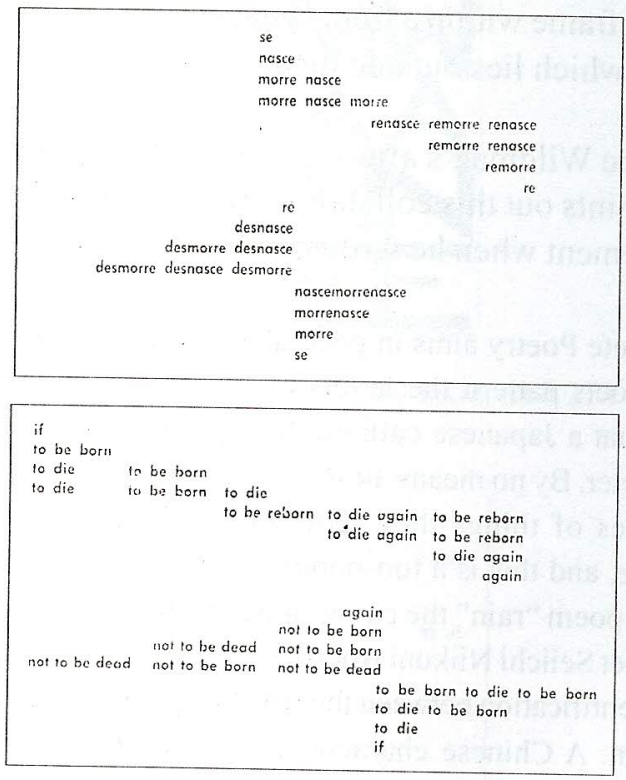

Figures $3 a$ and $3 b$ : "se nasce morre nasce" by Haroldo de Campos (Solt 1970:104) 


\section{silencio silencio silencio silencio silencio silericio silencio silencio silencio silencio silencio silencio silencio silencio}

Figure 4: "silencio" by Eugene Gomringer (Solt 1970:104)

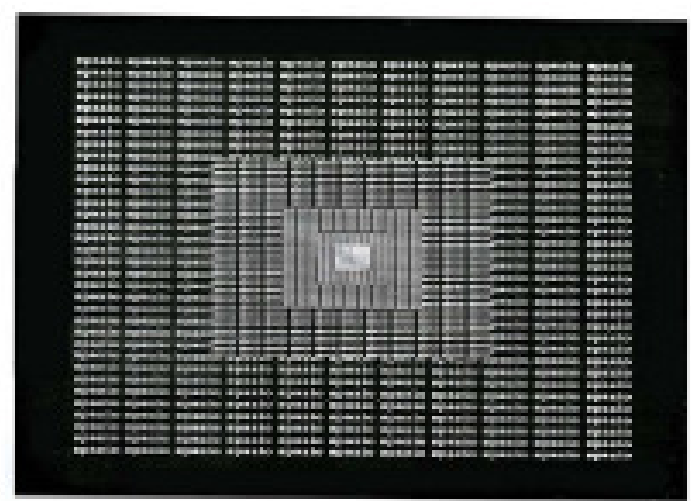

Figure 5: "spazio" by Arrigo Lora Totino (Solt 1970:104)

When one considers the translatability of Decio Pignatari's "beba coca cola" (Solt 1970:108), one needs to look at the use of Roman script and the language features at work.

Script features: usage of lower case. The ' $l$ ' in $b$ and ' $l$ ' and the shapes of 'e', 'a', 'c' and 'o' all complement one another. Language features heavily contribute to the construction of the poem: 
b e b a c c o c a c c o 1 a

- Using the same alphabets and combinations of these alphabets, the language itself provides the poem its poeticity and natural rhythm with the 'beba' and the 'babe' and the 'caco', 'coca', 'cola' and 'cloaca' all deriving from the combinations of the alphabets in "beba coca cola".

- When one approaches the English translation, the physical reproduction of the language patterns poses the problem although the script remains the same. However, because the script is the same, the visual intensity of the poem is not reduced greatly.

- The translation does show the cumulative effect of such similar looking words such as 'drink', 'drool' and 'cocaine'.

- Typographically, the vertical nature of the alphabets as well as the roundedness is retained by the l's and the o's.

- When we look at the translation of the poem we are considering: a faithful recreation of the same experience in "beba coca cola" which is supported by script - (visual and language semantic) features.

- The syntax in the source text and the target text is retained with the blank space contributing as the connecting element. The blank space visually specifies the relation that the verbs on the left have with the nouns on the right.

- However, as is the case with visual poems, the logical syntax is broken for dramatic impact and in the last three 'lines'/ 'non-lines' one has three nouns conveying the theme of the poem.

- Visually, the translation faithfully reproduces the 'I', $\mathrm{Z}$ and single word pattern except for the fact that the word 'glue' does not visually fit into the column as in the original which is a language constraint.

- The translation also chooses to reverse the color coding from white on red to red on white, which self-referentially calls attention to the poem as object and as translated object. 
Different scripts and different languages: An interesting example here is of Cummings' verse. In "brIght" (Solt 1970:217) note the capitalization which is specific to the Latin script. This has been translated by Augusto de Campos to "brIlha." However, any attempt at interlingual translation here must result in a significant visual loss: for instance in the Devanagari script, which does not possess a parallel capitalization. While the Japanese kana can make up for some loss by alternating its scripts Katakana and Hiragana, it has its own sets of constraints as it is a pure syllabary with independent linguistic signs and therefore a different kind of loss occurs here.

In R. K. Joshi's self referential texts, for instance, in 'tikon' and in 'chavakon' and in 'regh' (Figures 6,7,8), the script features of the Devanagari lend themselves to a poetic manifestation which cannot be visually translated by 'square' or 'line' although 'tri an gle' may work to some extent. The angularity or the circularity of the consonants as also the phonetic accompaniment to "ti ko n" as in "1 23 " or "cha va ko n" as in "1 234 " or in "re gh" as in " is visually derived from the nature of the script. A similar situation arises in Seiichi Niikuni’s "Mouth, Empty, Lie" (Solt 1970:161).

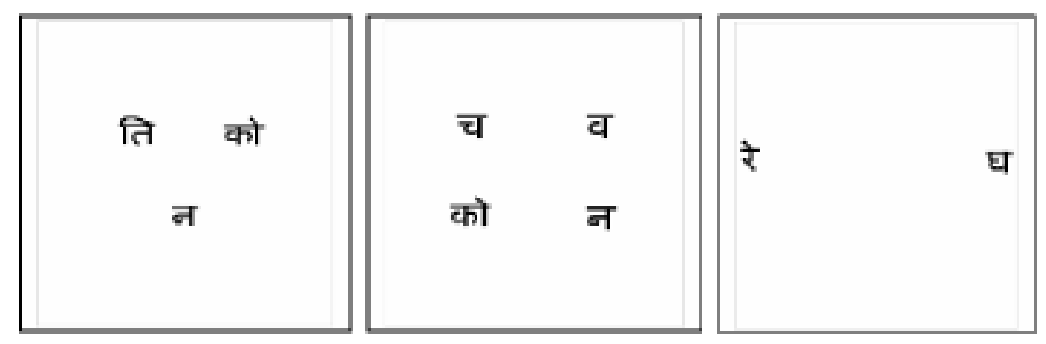

Figures 6, 7, 8: "tikon," “chavakon," "re gh" (Joshi 1972:1,2,4)

Thus, since script and language features carry a predominant significance in the visual poem, any notion of translatability must cover these two areas even before the translatability of the semantic content. Therefore concepts such as equivalence and loss/gain need to be related in the case of these poems not just to the semantic content but to the visible features of the text-script, typography and language. 


\section{The Nature of Script: Recreation of Visual Intensity in the Target Text}

"Epithalamium II" (Solt 1970:114) has been graphically transposed here into Marathi, Sanskrit, Tamil and Malayalam. In Pedro Xisto's poem, as has been pointed out earlier, the graphic structure of the poem is a tightly bound one. In this poem, the smaller size of the ' $h$ ' and the ' $\mathrm{e}$ ' and their encapsulation in the coiling ' $\mathrm{S}$ ' where, according to the key, $\mathrm{S}=$ serpents; $\mathrm{h}=$ homo; $\mathrm{e}=\mathrm{eva}$; has two themes, one specifically depicting the fall of man and the second a visual representation of the man-woman relationship; can be used to illustrate the translation possibilities that the script can open up.

To do this, let us consider translation of the visual structure into three Indian scripts: Devanagari, Malayalam and Tamil. Translation into Marathi and Sanskrit which use the Devanagari script shows how language aids script in providing linguistic elements which contribute to the script elements. In "to - tee" (he, she), for instance, the matra of 'to' can be ensconced in the 'Velanti' of 'tee' to recreate the visual parallel and thus visually translate the text (Figure 9). Similarly in Sanskrit, saha i.e. 'he' fits into sa i.e. 'she' (Figure 10). A similar transposition, almost paralleling a superimposition, has been attempted in the Malayalam and Tamil scripts which have the same words, avan and $a v a L$ for 'he' and 'she' (Figures 11 and 12).

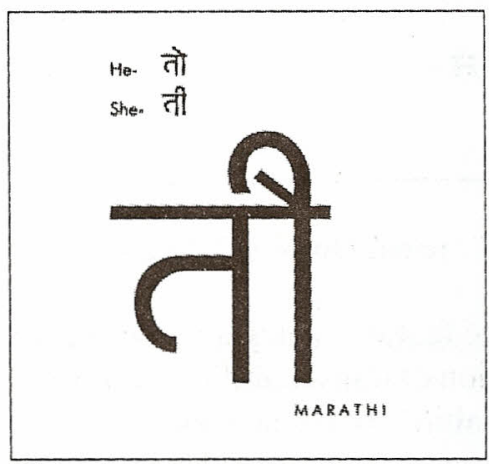

Figure 9: Graphic depiction

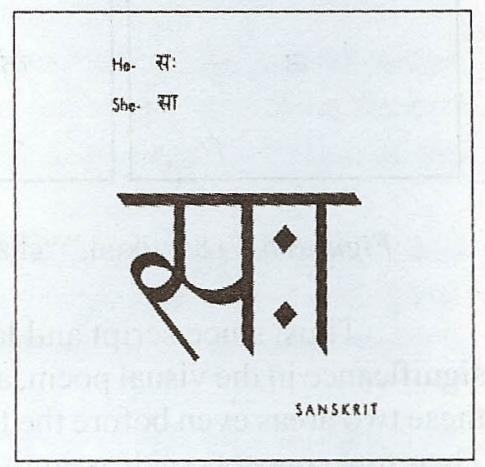

Figure 10: Graphic depiction 


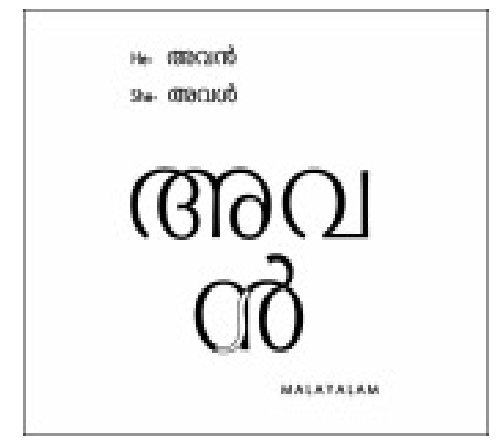

Figure 11: Graphic depiction

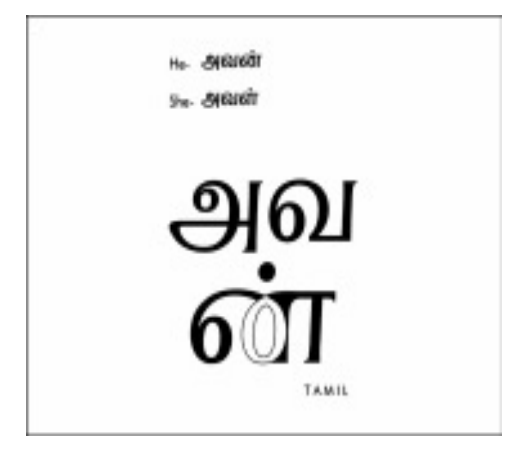

Figure 12: Graphic depiction

However, in all these cases, the untranslatability lies in the transfer of the general theme while the specificity of the Fall of Man cannot be visually reproduced unless one works in multimedia, where movement and suggestion could be imparted in several forms.

\section{Constructivist Visual Concrete Poems based on Non-Verbal Modes and the Nature of their Translatability}

Like other visual modes of expression such as painting, sculpture, audio-visual modes such as dance, cinema, drama and audio forms such as music, the visual concrete poem strives to provide a sensory experience to the viewer. This sensory experience is created in certain visual poems (also called "semiotic/code" poems by Decio Pignatari) with the use of extra-linguistic elements such as the kind seen in graphic design, logos, symbols in advertising etc. The viewing of some of these poems is facilitated by means of a key (which has language elements like words). Luiz Angelo Pinto's 'code poem' (Solt 1970:111) and Pedro Xisto's "Epithalamium III" (Solt 1970:115) could be cited here as examples.

Another type consists of poems which explore through minimalism. Heinz Gappmayer's “d u” (Figure 13), for instance, in 
which 'du' or 'you' is concretized by means of a visual binary within the form of the text itself, created by the black and white spaces marked by a diagonal. Similarly, in R.K. Joshi's "tee ki tuu?" ("she or you?") (Figure 14) the minimalism of the vertical 'maatra' which phonetically marks the 'aa' sound in Devanagari and the ' $u$ ' form iconically signify the interrogative stance in a female vs male binary. And a third type is of the rigorously constructivist kind which chooses to convey the sensory experience through their physical/formal structure. For instance, Mary E. Solt's "Moonshot Sonnet" (Solt 1970:242) which uses photographic markings. Similarly, Augusto de Campos' ÔLHO POR ÔLHO ("eye for eye") (Figure 15) is composed of magazine cutouts underscoring the visual through representations of 'eyes' of a wide spectrum of people such as politicians, stars, athletes, poets as also eyes of animals, birds and visual indicators such as traffic signs, the washer-eye of a machine etc. If we take up this last sub-category of extra-linguistic expression, such concrete texts pose the same problems for translatability as paintings do. It is a sensory experience and especially a compact, condensed concept that can seemingly only be interpreted or commented upon. Are these therefore not translatable? We can attempt to answer this by exploring the idea of intersemiotic transmutation/ transposition.

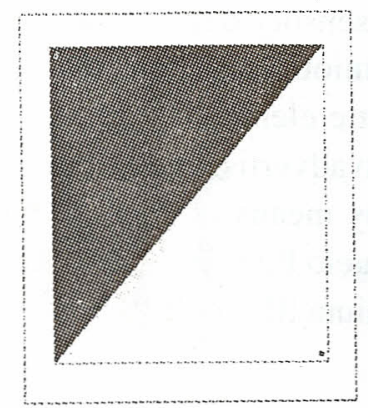

Figure 13: "du" by Heinz Gappmayr, Solt 135

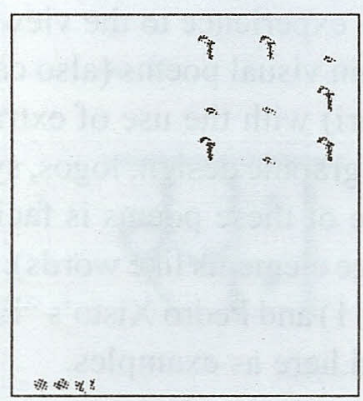

Figure 14: "tee ki tu?" by R.K. Joshi, Rava 6 


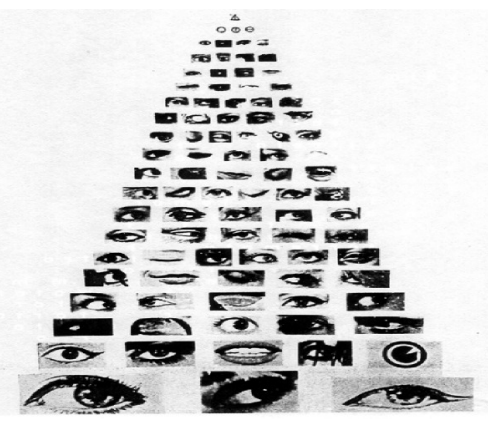

Figure 15: "ÔLHO POR ÔLHO” by Augusto de Campos,

Solt 98

\section{Intersemiotic Transposition}

The term derives from the often quoted typology given by Jakobson in his "On Linguistic Aspects of Translation" wherein he identifies 'intralingual', 'interlingual' and 'intersemiotic translation' or 'transmutation' (Brower 1959:233). Asimo suggests that intersemiotic translation implies a sort of subdivision of the original into various elements and the "identification of components able to translate said elements within the coherence of the translated text" (Asimo, "Intersemiotic Translation - Part Two") George Steiner argues for a 'totalizing' designation for a theory of translation, an all-inclusivity which marks the wideness of the 'potentially translatable':

A 'theory' of translation, a 'theory' of semantic transfer, must mean one of two things. It is either an intentionally sharpened, hermeneutically oriented way of the totality of semantic communication (including Jakobson's intersemiotic translation or "transmutation"). Or it is a subsection of such a model with specific reference to interlingual exchanges, to the emission and reception of significant messages between different languages... The "totalizing" designation is the more instructive because it 
argues the fact that all procedures of expressive articulation and interpretative reception are translational, whether, intraor interlingually.

(Steiner 1992:293-294)

An active claim in intersemiotic transposition is the need to address both verbal and visual aspects of expression. Such intersemioticity thus facilitates the opening up and interaction between individual systems which in a Derridean sense act as 'supplements'.? Thus, according to Ira Torressi in her paper titled "Translating the Visual: The Importance of Visual Elements in the Translation/Adaptation of Advertising across Cultures," print advertisements have to be adjusted to different cultures using suitable verbal and pictorial elements which,

should never be taken for granted or considered universal; their arrangement follows grammar-like rules... and produces a constructed and negotiated meaning which completes the meaning of verbal texts. In the field of advertising, therefore, translation skills should include the ability to 'translate' the visual as well as the verbal.

(Torressi "Translating the Visual" para:3)

Untranslatability then raises the following issues: If a text is recognised as 'untranslatable', does that mean that it simply must not be translated? Is this where notions of translation as 'interpretation' come into play especially in the case of intersemiotic transposition between two systems? When one is dealing with an extra-linguistic system, a systemic problem posed is that of a lack of exactly replaceable units. This, however, should be a given in the context of intersemiotic translation as no two semiotic systems can have such exact units facilitating equivalence. On the other hand, a certain loss is assumed and a certain gain in terms of enrichment or clarification is what needs to be aimed at. Thus, there exist degrees of untranslatability in terms of semantic equivalence in linguistic systems and in the case of nonverbal ones in an attribution owing to the non-existence of a double- 
articulation: the non-divisibility of the form into replaceable units of articulation. As Bruno Asimo puts it:

In intersemiotic translation, like in any kind of translation in general, instead of pretending that it is possible to translate or communicate everything, against the evidence, it is advisable to take the loss into account from the start and, consequently, to work out a translation strategy that rationally enables us to decide what are the most distinctive components of the text and, conversely, those that can be sacrificed in favor of the translatability of another aspect of the text... Textual translation follows the principle according to which an original can possibly have many different translations, all of them potentially accurate; such potentiality is even more developed in intersemiotic translation.

(Asimo "Intersemiotic Translation -Part 2" para:1)

Claus Cluver's “On Intersemiotic Transposition” (1989) examines this phenomenon in the context of verbal and visual texts. In his discussion on the nature of symbol systems, Cluver points out the difficulties in establishing a semantic equivalence between verbal and visual forms. But he believes that this does not render intersemiotic transposition impossible. He agrees that the units of a visual system such as painting cannot be as rule-governed as in verbal language. ${ }^{8}$ According to Cluver,

To transpose a painting into a verbal text is to reconstitute its meaning by creating a sign that draws on the codes and conventions of a literary (and not merely a linguistic) system equivalent to the pictorial system operative in the painting.

(Cluver 1989:61)

Thus he states that similar considerations are involved in intersemiotic transposition as in the case of inter-lingual transposition. He illustrates this with the act of the translator who may need to 
"sacrifice semantic equivalence on the linguistic level in order to foreground the semantics of the poetic system" and identify those signifying practices in the source system to find "equivalents in the system that is accessible to the audience" (Cluver 1989:61).

Thus, if we stick to the denotative aspects of the term 'translation', as we do in the case of intralingual/interlingual translation, we run into problems, as extra-linguistic systems possess their own structures and units which are not directly compatible with language. Jakobson too, thus, uses the term "transmutation." Film, painting, sculpture belonging as they do to the visual system possess certain shared characteristics such as: surface, plane, background, figure-field, perspective, movement, use of colour, sharpness, depth. It may be possible then to postulate that these shared characteristics which constitute the syntax of these forms can be used to bring about an intersemiotic transposition from one form into another.

\section{Possibilities in Intersemiotic Transposition in the Context of Visual Concrete Poems}

According to the "Pilot Plan for Concrete Poetry" (1958), a manifesto by the Noigandres group of Decio Pignatari, Haroldo de Campos and Augusto de Campos, visual concrete Poetry is based on a 'direct-analogical', not 'logical-discursive' juxtaposition of elements (Solt 1970:71). Any attempt at inter-semiotic transposition would have to express this analogical spirit. Secondly, if the visual elements in the visual concrete poem are in themselves not recognizable/identifiable units to the viewer, then a translation of these elements into another system can 'evoke' the meaning of the source system. ${ }^{9}$ Thus, in the case of constructivist visual concrete poems where the emphasis is on the physical form of the text and its constituents, intersemiotic transposition into another system could be an approach towards translating the 'experience' in the text. Bassnett points out: 
Equivalence in translation, then, should not be approached as a search for sameness" but rather as a "dialectic between the signs and structures within and surrounding the SL and TL texts (1980:29)

In the case of verbal to visual or visual to verbal as is the possibility that Jakobson's third category creates, there is one stable system viz language, which does not create too many choices in terms of the medium which could be writing or speech. However, when one takes up the visual, the myriad possibilities of media that can be used for this purpose indicate that there needs to be some justification of the particular medium that is ultimately chosen for this purpose. Thus, for instance, if one wishes to retain the frame of the compact structure and insert these textual elements in some form, then using a medium which uses or assumes a frame may best suit the transposition. However, creating a compartmentalized classification here would inhibit the transposition potential of the source text. And therefore, it may be best to experiment with different possibilities to achieve such intersemioticity.

\section{Transposition Possibilities}

For "if to be born" (Figures 3a and 3b) - cyclical movement - rotation of wheels, movement of feet - motion, ascent, descent, visual effects through the use of light, miming, movement through music.

For "silencio" (Figure 4) — binary — silence amidst noise; single foregrounded sound against host of competing sounds; foregrounding one colour through competing colours, digital simulation of space, silence, noise, activity.

For "du" (you) (Figure 13) - binary - alternating faces in drama - tragedy/comedy; movement of hands — tight-fisted/open; sound effects - cascading waterfall/ river water lapping at edges of the bank, long pause between two modes of music. 
For "tee ki tuu?" (Figure 14) — binary — alternating sounds of objects of different intensity, pitch, bird sounds; conversion of interrogation into eye movements - dance, miming, use of gestures, alternating female-centric and male-centric performances from different cinematic sequences.

\section{The Visual Concrete Poem as Intersemiotic Transposition in itself}

Claus Cluver refers to Concrete poems as intersemiotic transpositions in being "intermedia works in which the verbal text has been integrated into the new sign" (84). He adds to this the example of the "advertising logo" which "can be viewed as transmutations of letters...into iconic signs of the objects or activities they stand for" (87). Thus intermediality approaches the condition of intersemioticity.

However, we can also identify another category. Some visual poems are created as 'homage' to the works of other visual artists especially painters or are homages to other visual poems or texts. The former are examples of transposition from one medium within the visual system into another. However, for a viewer non-conversant with the style of the source text i.e., the painting that is implicitly referred to in the visual poem, language is used for translation and interpretation in the commentary on the first and second texts. Thus inter-semiotic translation here is three-tiered or multi-leveled and reveals the complexity of the process.

For example, in Ian Hamilton Finlay's "Homage to Malevich" -"blockblack" (Figure 16), the allusion is to Kasimir Malevich's Homage to the Square series. Where on the first level, Malevich, the Suprematist painter, is expressing a homage to the 'squareness' of the signifier 'square', Finlay's transposition is based on the Concretist's exploration of the signifiers 'lock', 'black' and 'block' and 'lack'; through the interplay of the signifiers used, where the blackness of Malevich's square is underscored by the usage of blank space between the letterforms. Other examples of this inter-semioticity are Shutaro 
Mukai's "Homage to Kitasono Katsue's "shiro" (See Mukai, "Morphopoeisis II") and R. K. Joshi's "Vishrantisthane... James Joyce Shaapit" (See Rava 1972:11)

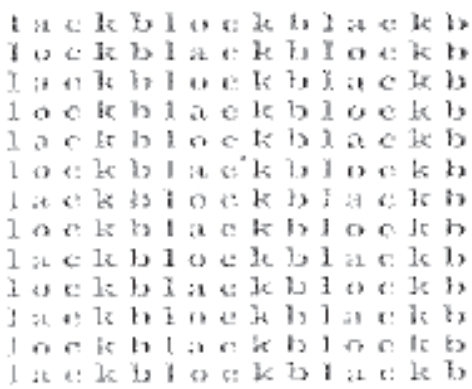

Figure 16: "blockblack” by Ian Hamilton Finlay (Bann 1967:141)

\section{Conclusion}

The blurring of boundaries between translation and interpretation brings us back to fundamental issues: Is creation itself an act of transposition, where the artist/ the musician/the performer thus translate sensory experiences in the world into a communicative form? Re-oriented thus, the work of art becomes the Target System and all that operates in its making is the Source. It follows that any enquiry into the nature of translatability needs to go further beyond the physical text itself. Thus, the Visual Concrete poet's transposition of the concept of 'space' to the signifying blank space on the page, which co-exists and interacts with the formal features of the letterforms and other elements used, is already an inter-semiotic phenomenon.

Extra-linguistic systems pose new questions in the context of Translation Studies and occupy a different space and demand a reexamination of the act of translating, the nature of translatability and the nature of the translation itself. What criteria can one apply to the 
selection of a suitable medium for transposition? Does this depend on the receptivity potential of the viewer/reader or on the nature of the source?

Visual art forms such as painting, sculpture, calligraphy, popart are dynamic and viewer-specific entities. The sign functions that these involve therefore constitute what Eco calls 'Open Works'. He defines an 'open work' as one that

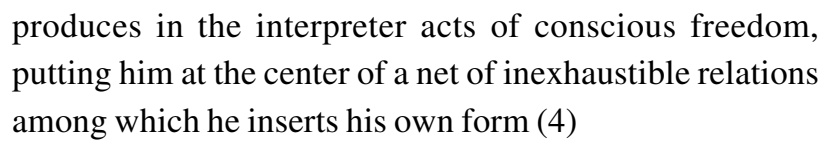

In a more radical manner, Barthes' definition of the 'writable' text in $S / Z$ (1974) explores the 'plural' of the text. Any attempt at translating the units contributing to such dynamism cannot be limited therefore to linguistic approaches, to the concept of the text. The enquiry here has focused upon a formalistic approach to the compositional features of Visual Concrete Poetry, its inter-mediality and issues of translatability thereof.

Visual Concrete Poems which are language-based involve the use of a particular script and a particular text. The act of translation would therefore seem to be related to the transfer of semantic content from the source language to the target language. However, in the case of Visual Concrete Poems, even in the case of those that are textbased (leaving aside for a while the structural complexity of those texts which are particularly form-based) since the script and the typological devices at work are an intrinsic part of the text, an integral part of the textual intentionality at work; the act of translation would have to take into account not simply the semantic content but the visuality of the text, its intermediality. The text is in a 'visualogue' 10 with the viewer and therefore translation cannot overlook this aspect of the text. Visual concrete poetry's intermediality and its responsiveness to intersemiotic exchange thus points to a more fluid 
approach towards translatability. Issues of untranslatability or issues related to relativity of semantic transfer in systems other than language indicate a dynamic site where linguistic-cultural-semiotic factors intervene to create complex situations and thereby undermine any notion of a stable ground or closure that the activity of translation may seek to define.

\section{Notes}

1. Poet and critic Dick Higgins was the first to use the term 'intermedium' to describe Concrete Poetry. In Visual Concrete Poetry, the visually presented linguistic symbols also work as graphic forms. Higgins points out that the word 'intermedia' is used by Samuel Taylor Coleridge in 1812 "in exactly its contemporary sense-to define works which fall conceptually between media that are already known ..." (Higgins 1984:52).

2. Visual forms like painting, sculpture etc belong to a visual system of expression using verbal and non-verbal modes and structures based on visual strategies of creation. These are viewed parallel to language as a system possessing a grammar. However, the nature and the scope of a 'visual grammar' poses certain theoretical problems. The debate on this application continues with an insistence on the 'pictorial turn' as against the 'linguistic turn' in theory. See W.J.T. Mitchell's Picture Theory (1994) and Mieke Bal and Norman Bryson's (1991) 'Semiotics and Art History,' The Art Bulletin 73.2:174-208.

3. Other typologies for the concept of 'equivalence' are those given by Popovic (four types: linguistic, paradigmatic, stylistic and textual) and Nida's formal and dynamic kinds (Bassnett 1980:25-26).

4. See Dick Higgins' (1987) Pattern Poetry: Guide to an Unknown Literature, State University of New York Press.

5. Although Cummings' name appears in the lower case in several places, the E E Cummings Society believes that his name should be capitalized. For the debate on capitalization of Cummings' name, see: <http://www.gvsu.edu/english/cummings/caps.html> 
6. The Concrete Poetry Movement was also a result of the influences of contemporaneous movements in art and their philosophies. In particular, direct links can be established with Concrete art. However, the Concrete Art Movement itself consisting of artists such as Piet Mondrian and Max Bill in turn evolved through influences operating right from the Post-impressionists such as Cezanne and Van Gogh with their bold, unrealistic colours through Expressionists such as Kandinsky and Klee with their minimalistic use of line and colour, and especially the Cubists such as Picasso, Duchamp and Braque with their multiple perspectives and use of geometric shapes, the 'anti-art' of Dadaism to particular movements such as Suprematism and especially Constructivism with their radical, abstract approach to space and form. These movements explored the material nature of the machine age and the artists believed that new ways were required to interpret the dynamic changes ushered in by Modernism and Industrialization. These movements demonstrated that visual elements such as line, colour, shape and texture possess their own ontological expression. In the fine arts, Constructivism led to other directions such as Abstract Creation group, Kinetic sculpture, Luminism, Op art, Minimalism and Concrete Art which in turn inspired the Concrete Poetry Movement.

7. The term is used as a fundamental starting point by Stephen Scobie in his Earthquakes and Explorations: Language and Painting from Cubism to Concrete Poetry (1997) to show how the relationship between language and painting is one of "mutual dependence, cohabitation, necessary implication" (Scobie 1997:3)

8. The nature of 'units' in visual systems has been vigorously debated. Swedish Semiotician Goran Sonesson remarks: "Considered in themselves, the lines and surfaces making up a picture are indeed deprived of meaning, just as phonemes are; but whereas the phonemes, once they have been put together to form a word, continue to lack separate meaning, pictorial traits take on, and distribute among them, the global meaning of the whole configuration. Thus, in the world 'face', the first letter is not the carrier of the meaning 'hair', the second of the meaning 'forehead', etc, but that is precisely the case with the lines making up the drawing of a face." ("Image/Picture") 
9. While commenting on the difficulty of achieving equivalence of code-units in inter-lingual translation, Jakobson points out how messages can act as an "adequate interpretation of alien code units." (Jakobson in Brower 1959:233)

10. The theme of the XX Icograda Congress at Nagoya, Japan, October 2003. http://nagoya.icograda.org <www.visualogue.com> (29 August 2004)

*Author's Note: I must offer my apologies for not being able to reproduce all illustrations with the text of this paper. This is due to the difficulty encountered in communicating with and acquiring permissions from individual copyright holders, heirs and executors. Visit < www.ubu.com $>$ for a glimpse into the vast field of Visual Poetics.

\section{Acknowledgements}

Figure 1 Reprinted with the permission of the literary estate of Ronald Johnson

Figures 2, 6, 7, 8, 14 Reprinted with the permission of Mrs. Mangala R. Joshi

Figures 3a, 3b Reprinted with the permission of Prof. Ivan Persio de Arruda Campos

Figure 4 Reprinted with the permission of Prof. Eugen Gomringer

Figure 5 Reprinted with the permission of Mr. Arrigo LoraTotino

Figure $13 \quad$ Reprinted with the permission of Prof. Heinz Gappmayr

Figure 15 Reprinted with the permission of Mr. Augusto de Campos

Figure 16 Reprinted with the permission of the estate of Ian Hamilton Finlay 


\section{References}

Abrams, M.H. (1993) A Glossary of Literary Terms ( $6^{\text {th }}$ ed.), Harcourt Brace and Bangalore: Prism Books.

Asimo, Bruno (23 July 2004) 'Intersemiotic Translation - Part One' $\leq \mathrm{http}$ :// w w w logos.it/pls/dictionary/ linguistic_resources.cap_1_36_en?lang=en>

Asimo, Bruno (23 July 2004) 'Intersemiotic Translation - Part Two' $\leq \mathrm{http}: / / \mathrm{w}$ w w 1 ogos.it/pls/dictionary/ linguistic_resources.cap_1_37_en?lang=en>

Bal, Mieke and Norman Bryson (1991) 'Semiotics and Art History', The Art Bulletin 73(2): 174-208.

Bann, Stephen (1967) Concrete Poetry: An International Anthology, London: London Magazine Edition.

Barthes, Roland (1974) S/Z, trans. Richard Miller, New York: Hill and Wang.

Bassnett-McGuire, Susan (1980) Translation Studies, London: Methuen.

Cluver, Claus (1982) 'Reflections on Verbivocovisual Ideograms', Poetics Today 3 (3):137-148.

Cluver, Claus (1989) ‘On Intersemiotic Transposition', Poetics Today 10 (1):55-90.

Eco, Umberto (1989) The Open Work, New York: Hutchinson.

Higgins, Dick (1984) Horizons: The Poetics and Theory of the Intermedia, Carbondale: Southern University Press.

Jakobson, Roman (1959) 'On Linguistic Aspects of Translation' in Reuben A. Brower (ed.) On Translation Cambridge, Massachusetts: Harvard University Press. 
Joshi, R.K. (1972) ‘Aksharkaar 'Ashya’ Kavita’, Rava (10):1-6, 8, 11.

Kaindl, Klaus and Riitta Oittinen (2004 (23 July)) 'The Verbal, The Visual, The Translator'

$<$ http://www.iatis.org/content/korea/panel7-verbalpanel.php>

Massin, John (1970) Letter and Image, trans. Caroline Hillier and Vivienne Menkes, London: Studio Vista.

Mitchell, W.J.T. (1994) Picture Theory, Chicago: University of Chicago Press.

Scobie, Stephen (1997) Earthquakes and Explorations: Language and Painting from Cubism to Concrete Poetry, Toronto: University of Toronto Press.

Sebeok, Thomas A. (1986) Encyclopedic Dictionary of Semiotics, Mouton de Gruyter.

Shutaro, Mukai Morphopoiesis II, Japan.

Solt, Mary Ellen (ed.) (1970) Concrete Poetry: A World View, Bloomington: Indiana University Press.

Sonesson, Göran (13 February 2006) 'Image/Picture', The Internet Semiotics Encyclopedia.

$<$ http://www.arthist.lu.se/kultsem/encyclo/image_picture.html>

Steiner, George (1992) After Babel: Aspects of Language and Translation, Oxford: Oxford University Press.

Weaver, Mike (1976) 'Concrete Poetry', Visible Language 6:293326

Wildman, Eugene (ed.) (1969) Anthology of Concretism, Chicago: The Swallow Press Inc. 